\title{
Mapping wear modes of composite materials with intermetallic reinforcing based on antifrictional alloy of system Al-Sn-Cu
}

\author{
P. A. Bykov ${ }^{\dagger, 1}$, I.E. Kalashnikov ${ }^{1}$, L. I. Kobeleva ${ }^{1}$, I. V. Katin ${ }^{1}$, R. S. Mikheev ${ }^{2}$ \\ †pbykov@imet.ac.ru \\ ${ }^{1}$ Baikov Institute of Metallurgy and Materials Science, RAS, Moscow, 119334, Russia \\ ${ }^{2}$ Bauman Moscow State Technical University, Moscow, 105005, Russia
}

Tribological properties of a composite material with intermetallic reinforcing based on an antifriction alloy of Al-Sn-Cu system are studied. The samples were obtained by the method of reaction casting mixing micron-sized titanium particles into the melt of the matrix alloy. The formation of intermetallic phases led to an increase in the hardness and a decrease in the wear rate of the sample of composite material. Dry sliding wear tests were carried out using a fixed sleeve (counterbody made of steel 45) against a rotating disk (composite material) at sliding velocities of $0.25,0.5,0.75 \mathrm{~m} / \mathrm{s}$ and loads $0.5,1,1.5,2$, 2.5, $3 \mathrm{MPa}$. Wear rate of the samples and friction coefficient for the entire set of tribo-loading parameters were determined. A general increase in the wear intensity with increasing test load was shown. There was no general tendency of the change in the wear rate with the increasing test velocity. The change in the friction coefficient during the test made it possible to determine the wear modes. The temperature change in the friction process was an additional parameter for describing the wear modes. An increase in load and velocity led to an increase in the friction temperature, in addition, the rate of temperature change was significantly influenced by the test time for equal friction paths. Maps of the wear rate which determine the wear modes during testing are constructed. The bounds and conditions of changes between the four modes of wear, soft, mild, severe and critical, are shown. Optimal loading parameters of the friction process corresponding to the sliding velocity $0.5 \mathrm{~m} / \mathrm{s}$ and load $1.5 \mathrm{MPa}$ are determined. The constructed wear maps made it possible to determine the friction regimes under which the exploitation of the composite material studied will be carried out in the region between soft and mild wear regimes.

Keywords: composite materials (CM), dry sliding, wear map, wear rate, aluminum, $\mathrm{Al}_{3} \mathrm{Ti}$ intermetallic.

УДК: 621.893

\section{Картирование режимов трения композиционных материалов с интерметаллидным упрочнением на основе антифрикционного сплава системы Al-Sn-Cu}

\author{
Быков П. А. ${ }^{\dagger}$, , Калашников И. Е. ${ }^{1}$, Кобелева Л. И. ${ }^{1}$, Катин И. В. ${ }^{1}$, Михеев Р. С. ${ }^{2}$ \\ ${ }^{1}$ Институт металлургии и материаловедения им. А. А. Байкова РАН, Москва, 119334, Россия \\ ${ }^{2}$ Московский государственный технический университет имени Н.Э. Баумана, Москва, 105005, Россия
}

Исследованы трибологические свойства композиционного материала с интерметаллидным упрочнением на основе антифрикционного сплава системы Al-Sn-Cu. Образцы изготавливали методом реакционного литья, путем замешивания частиц титана микронного размера в расплав матричного сплава. Образование интерметаллидных фаз вело к повышению твердости и снижению интенсивности изнашивания образца композиционного материала. Испытания на сухое трение скольжения проводили по схеме торцевого нагружения неподвижной втулки (контртело из стали 45) против вращающегося диска (композиционный материал) при скоростях скольжения 0.25, $0.5,0.75$ м/с и нагрузках $0.5,1,1.5,2,2.5,3$ МПа. Трибологические свойства образцов (интенсивность изнашивания и коэффициент трения) определяли для всего набора параметров трибонагружения. Показано общее увеличение интенсивности изнашивания с увеличением нагрузки испытания. Отсутствует общая тенденция изменения интенсивности изнашивания при увеличении скорости испытаний. Изменение коэффициента трения в процессе испытания позволяло определять режимы изнашивания. Изменение температуры являлось дополнительным 
параметром для описания режимов изнашивания. Увеличение нагрузки и скорости вело к повышению температуры трения, кроме этого, на скорость изменения температуры значительное влияние оказывало время испытания, при условии равенства пути трения. Построены карты интенсивности изнашивания, определяющие режимы изнашивания в процессе испытания. Показаны границы и условия смены четырех режимов изнашивания: мягкий, умеренный, жесткий и критический. Определены оптимальные параметры процесса трения соответствующие скорости 0.5 м/с и нагрузке 1.5 МПа. Построенные карты трения позволяют определять режимы трения, при которых эксплуатация исследованного композиционного материала будет осуществляться в области между мягким и умеренным изнашиванием.

Ключевые слова: композиционные материалы (КМ), сухое трение скольжения, карты трения, интенсивность изнашивания, алюминий, интерметаллиды $\mathrm{Al}_{3} \mathrm{Ti}$.

\section{1. Введение}

Ежегодное производство подшипниковых вкладышей достигает более $10^{9}$ шт, что говорит о важности данного вида продукции для мировой промышленности. Мягкие трибологические сплавы на основе олова, свинца и алюминия, широко используются в опорах подшипников скольжения, но детальные исследования характера изнашивания и микроструктуры в таких материалах редки, так как подобные антифрикционные материалы не предполагают значительного износа [1]. К таким материалам предъявляются противоречивые требования относительно рабочей поверхности подшипника, которая непосредственно подвергается износу. С одной стороны, поверхностный слой должен обладать твёрдостью для повышения износостойкости, а с другой - должен быть мягким для снижения коэффициента трения [2].

Все применяемые подобные трибологические сплавы были разработаны в первой половине 20-го века. В настоящее время не наблюдается значительного прогресса в вопросах производства таких материалов или улучшения их свойств, несмотря на появление новых теорий и инструментов исследований. Это следует из анализа научных обзоров и статей, опубликованных по данному вопросу за последние годы [1,3-5].

Данная ситуация обусловлена тем, что при применяемых параметрах трибонагружения мягкие трибологические сплавы не испытывают значительного износа. Неверно говорить, что такие материалы не изнашиваются, но в правильно спроектированных узлах и стандартных условиях эксплуатации они могут сохранять свои технологические свойства в течение всего срока службы изделия $[3,4]$.

Однако несущая способность существующих трибологических сплавов ограничивает проектирование новых узлов трения, отвечающих растущим требованиям экономичности, качества и эффективности.

Так, одно из перспективных направлений в разработке новых конструкционных материалов - создание гетерогенных структур, представляющих собой различным образом организованные композиции из армирующих наполнителей и металлической матрицы [6-9]. Однако, при использовании композиционных материалов (КМ) в узлах трения скольжения целенаправленному выбору состава и технологии их производства должно предшествовать исследование закономерностей трибологического поведения материалов при различных видах нагружения, позволяющее осуществить прогнозирова- ние работоспособности узлов трения [10]. Изнашивание КМ имеет ряд особенностей $[11,12]$. В общем случае наличие в пластичных металлических матрицах твердых дисперсных частиц повышает износостойкость сплавов. Увеличение содержания и размера армирующих частиц в КМ ведет к уменьшению в общей поверхности трения площади участков матрицы, склонной к схватыванию. Высокопрочные частицы защищают матрицу от механического уноса материала, что ведет к уменьшению изнашивания КМ. Гетерогенность КМ способствует расширению области существования во фрикционном контакте так называемых вторичных структур, обеспечивающих протекание процессов трения и изнашивания в широком диапазоне нагрузок и скоростей [13-18].

При трибологических испытаниях протекание процесса трения зависит от нагрузки, геометрии трибоконтакта, относительного движения поверхностей контакта, скорости скольжения, шероховатости трущихся поверхностей, типа материала, жесткости системы, температуры, относительной влажности, вибрации т.д. Основное значение среди этих факторов имеют скорость скольжения и прикладываемая нагрузка [19].

Ранее, авторы данной статьи проводили исследования процесса трения для алюмоматричных КМ [20]. Были проведены испытания на сухое трение скольжения образцов из технически чистого алюминия и КМ на его основе, упрочненных частицами керамики и интерметаллидными фазами. Результаты испытаний выявили два основных режима, определяемых как мягкое, для которого характерно абразивное или окислительное изнашивание, и жёсткое трение, сопровождающиеся усталостным или адгезионным изнашиванием. Об изменении режима трения с мягкого на жёсткий судили по изменению интенсивности изнашивания и температуры в зоне трибоконтакта поверхностей. При мягком режиме в зоне трибоконтакта устанавливалось температурное равновесие. При жестком режиме трения температура в зоне трибоконтакта непрерывно росла. Армирование керамическими частицами $\mathrm{SiC}$ и интерметаллидными фазами эффективно расширяет диапазон трибонагружения. Наибольшее сопротивление изнашиванию и наиболее высокие допустимые температуры в зоне трибоконтакта имеют образцы КМ с полиармированием, в которых присутствуют интерметаллидные и керамические фазы.

Цель настоящей работы: изучить поведение образцов КМ на основе сплава АОМ20-1 при трении против 
контртела из стали в различных условиях нагружения, определить условия изменения режимов трения, построить трибологические карты.

\section{2. Материалы и методы исследования}

Образцы КМ были изготовлены методом механического замешивания армирующего материала в матричный расплав. Для армирования использовали порошок титана, с размером частиц 300-400 мкм в количестве 3 масс.\%, который вводили в расплав АОМ20-1 (17-23 масс.\% Sn; 0.7-1.2 масс.\% Cu; $\mathrm{Al}$ - остальное по ГОСТ 14113-78), нагретый до $750^{\circ} \mathrm{C}$ и перемешивали в течение 10 мин при скорости вращения импеллера 100 мин $^{-1}$. После выстаивания композиционного расплава в течение 20 минут с его поверхности удаляли оксидную пленку, перемешивали в течение 5 минут и проводили разливку расплава при температуре $700-750^{\circ} \mathrm{C}$ в графитовые и медные формы диаметром 28 мм и высотой 130 мм.

Трибологические испытания образцов проводили в условиях сухого трения скольжения на установке CETR UMT Multi-Specimen Test System по схеме осевого нагружения: неподвижная втулка (контртело) из стали 45X (HRC > 63) против вращающегося диска (исследуемый образец). Размеры стальной втулки: внутренний диаметр 12 мм, наружный диаметр 16 мм. Размер диска образцов: диаметр 20 мм, толщина 12 мм. Испытания каждого образца проводили при осевых нагрузках $0.5,1$, $1.5,2,2.5,3 \mathrm{MПа,} \mathrm{скорость} \mathrm{испытания} \mathrm{составляла} \mathrm{0.25,}$ 0.5, 0.75 м/с для каждого набора нагрузок. Путь трения при каждой осевой нагрузке составлял 450 м. Потерю массы $\Delta m$ образцов фиксировали после каждой осевой нагрузки путем взвешивания образца на аналитических весах. Степень износа образцов при сухом трении скольжения оценивали по величине интенсивности изнашивания $\operatorname{Im}=\Delta m / L$, где $L-$ путь трения. Так как, схема нагружения не позволяла установить термопару непосредственно на поверхности трения, фиксировали изменения температуры на контртеле, что позволило достаточно точно определять температурные скачки для описания процесса трения.

\section{3. Результаты и обсуждение}

Сплав АО20-1 относится к группе антифрикционных материалов, в которых мягкая фаза присутствует внутри композиции и выжимается на трущиеся поверхности в результате пластической деформации металла. Согласно, диаграммам состояния и проводенным исследованиям [21] при введении в расплав реакционно-активных порошков титана при температурах процесса введения и выдержки, должно образовываться только интерметаллидное соединение $\mathrm{Al}_{3} \mathrm{Ti}$. Исследования структуры и физико-механических свойств, проведенные в работе [22], показали, что метод механического замешивания дискретных реакционноактивных добавок титанового порошка позволяет его ввести, равномерно распределить и сформировать упрочняющие интерметаллидные фазы в объеме закрис- таллизовавшихся КМ. Взаимодействие титана с алюминием приводит к образованию интерметаллидных фаз. Наиболее термодинамически стабильной является фаза состава $\mathrm{Al}_{3} \mathrm{Ti}$, служащая мощным инициатором зародышеобразования. Сочетание интенсивного перемешивания и выдержки расплава с введенными в него реакционно-активными порошками титана губчатого строения, имеющими большую удельную поверхность, позволяет сформировать композиционный материал с матрицей, упрочненной интерметаллидными частицами $\mathrm{Al}_{3} \mathrm{Ti}$. Увеличение объёма вводимого порошка титана обеспечивает увеличение количества образующихся интерметаллидов.

Наряду с модифицирующим влиянием, фаза $\mathrm{Al}_{3} \mathrm{Ti}$ обладает повышенным уровнем твердости. Более дисперсная зеренная структура, а также образование интерметаллидов в материале обеспечило повышение твердости КМ на 20 - 25\% по сравнению с промышленным сплавом. Образец КМ, содержащий 3 масс.\% Тi и имеющий максимальную твердость, кристаллизация которого проходила в медном тигле, имел наименьшую интенсивность изнашивания. Поэтому КМ с данным составом был выбран для испытаний с целью построения карт трения в данной работе. На Рис. 1 представлена микроструктура образца КМ и данные PCMА интерметаллидных фаз $\mathrm{Al}_{3} \mathrm{Ti}$.

Интенсивность изнашивания рассчитывали для каждого набора параметров скорости и нагрузки. Рис. 2 иллюстрирует изменения интенсивности изнашивания образцов в зависимости от прилагаемой нагрузки. Общая тенденция к увеличению изнашивания образцов с увеличением прилагаемой нагрузки прослеживается для всего ряда выбранных нагрузок. Отметим, что при скорости $0.25 \mathrm{~m} / \mathrm{c}$ значения интенсивности изнашивания увеличиваются плавно, в то время как при скорости $0.5 \mathrm{~m} / \mathrm{c}$ происходит резкое увеличение изнашивания при нагрузке 3 МПа, а для скорости 0.75 м/с резкая потеря массы образца происходит при нагрузке 2 МПа. Эти изменения могут свидетельствовать о смене режимов изнашивания с «мягкого» на «жесткий».

Влияние скорости испытаний на интенсивность изнашивания не имеет общей тенденции. Так при минимальной скорости испытания 0.25 м/с наблюдается относительно небольшая потеря массы образца во всем

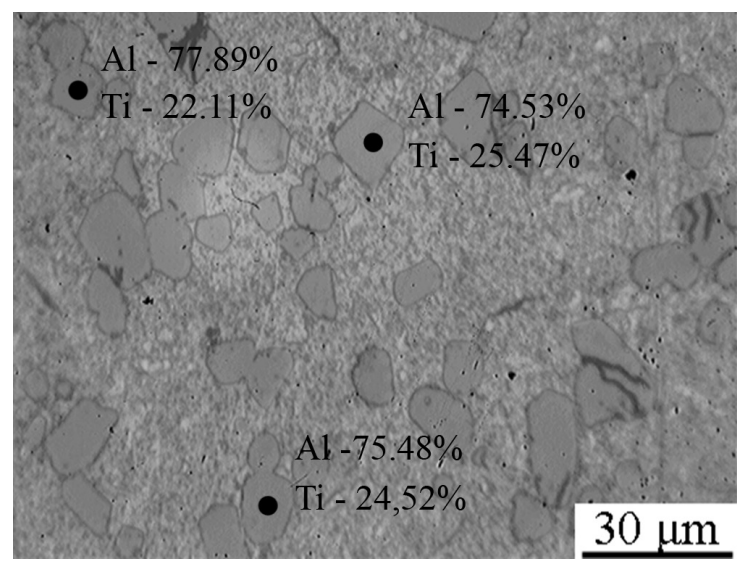

Рис. 1. Структура образца КМ и данные РСМА (масс.\%).

Fig. 1. Structure of the CM sample and XRS data (wt.\%). 


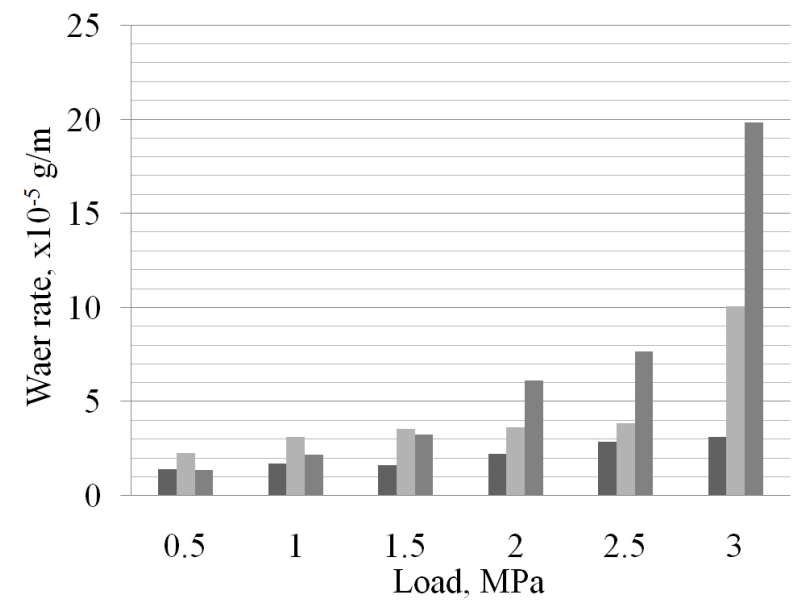

Рис. 2. Изменение интенсивности изнашивания в зависимости от нагрузки при различных скоростях: - $0.25 \mathrm{~m} / \mathrm{c}$, 口 $0.5 \mathrm{M} / \mathrm{c},-0.75 \mathrm{M} / \mathrm{c}$.

Fig. 2. Change in wear rate depending on load at different velocity: $-0.25 \mathrm{~m} / \mathrm{s},-0.5 \mathrm{~m} / \mathrm{s},-0.75 \mathrm{~m} / \mathrm{s}$.

диапазоне нагружения. В то же время при скорости $0.75 \mathrm{~m} / \mathrm{c}$ для нагрузок до 2 МПа интенсивность изнашивания меньше, чем при скорости $0.5 \mathrm{~m} / \mathrm{c}$. При скорости 0.75 м/с, начиная с нагрузки 2 МПа, начинается резкая потеря массы образца.

Рис. 3 иллюстрирует поведение коэффициента трения в зависимости от нагрузки при разных скоростях. Процесс трения при скорости 0.25 м/с можно описать следующими этапами: приработка при минимальной нагрузке, для которой характерно абразивное изнашивание и повышенный коэффициент трения, сменяется окислительным изнашиванием с понижением коэффициента трения при увеличении нагрузок. Процесс трения при нагрузке выше 2 МПа может свидетельствовать о формировании/разрушении «тела трения», в результате которого в зону трения попадают отслоившиеся частицы материала (процесс деламинации), что ведет к росту коэффициента трения. Дальнейшее увеличение

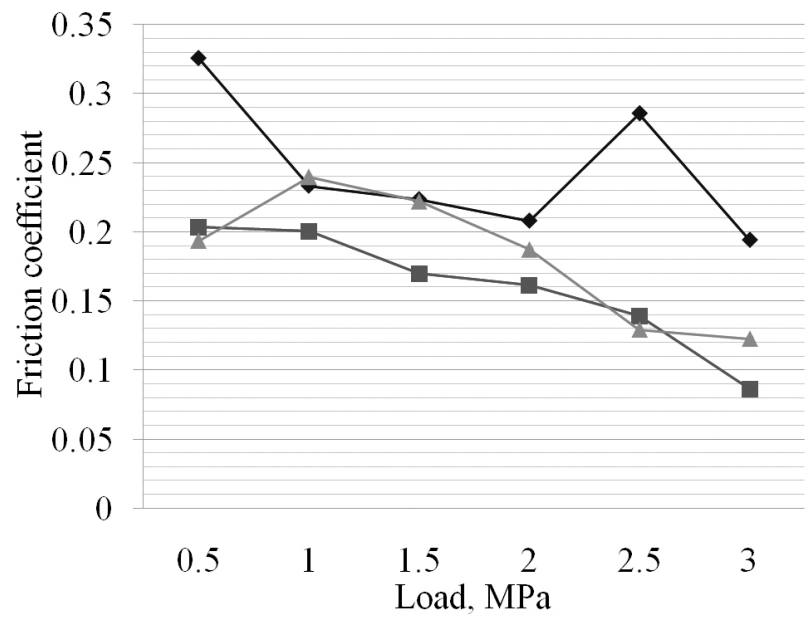

Рис. 3. Изменение коэффициентов трения в зависимости от нагрузки при различных скоростях: $-0.25 \mathrm{M} / \mathrm{c}$, - $0.5 \mathrm{~m} / \mathrm{c}, \Delta-0.75 \mathrm{M} / \mathrm{c}$.

Fig. 3. Change in coefficient of friction depending on load at different velocity: $-0.25 \mathrm{M} / \mathrm{c}, \boldsymbol{\nabla}-0.5 \mathrm{~m} / \mathrm{c}, \boldsymbol{\Delta}-0.75 \mathrm{~m} / \mathrm{c}$. нагрузки ведет к повышению температуры в зоне трения и размягчению материала, вследствие чего происходит понижение коэффициента трения.

При скоростях 0.5 и 0.75 м/с процесс приработки и выглаживания поверхности проходит быстрее, чем при скорости 0.25 м/с, что характеризуется меньшим коэффициентом трения. Формирование «тела трения» при увеличении нагрузок снижает коэффициент трения. Как и в случае со скоростью 0.25 м/с, повышение температуры в зоне контакта с увеличением нагрузки размягчает материал, что продолжает снижать коэффициент трения.

Анализ температуры процесса трения дает дополнительную информацию для оценки режимов изнашивания. Рис. 4 показывает характер изменения температуры в процессе трения при разных скоростях в зависимости от нагрузки.

Как видно из рисунка, увеличение нагрузки ведет к повышению температуры. Увеличение скорости испытаний по-разному влияет на изменения температуры. Так, при скоростях 0.25 и 0.75 м/с изменения температурных кривых имеют одинаковую тенденцию (при увеличении скорости скольжения температура равномерно растет), но при скорости $0.5 \mathrm{~m} / \mathrm{c}$ после нагрузки 1.5 МПа происходит резкое увеличение температуры.

С учетом равенства пути трения при всех скоростях, данное явление можно объяснить разным временем контакта трущихся поверхностей. В общем случае повышение скорости испытания ведет к повышению скорости нагрева. При скорости 0.25 м/с температура зоны контакта не достигала высоких значений из-за низкой скорости нагрева при всем наборе нагрузок. При скорости $0.5 \mathrm{~m} / \mathrm{c}$ наблюдается повышение скорости нагрева, после нагрузки $1.5 \mathrm{MПа} \mathrm{происходит} \mathrm{накопление}$ тепловой энергии в зоне трения, что приводит к резкому изменению температуры. При скорости 0.75 м/с за счет меньшего времени испытания тепловая энергия не успевала накапливаться, поэтому не наблюдалось резкого изменения температуры.

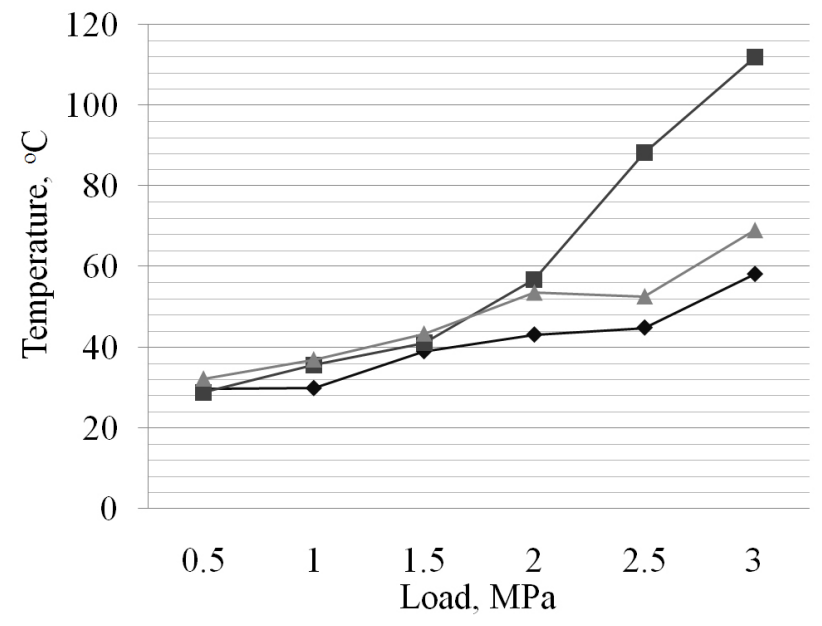

Рис. 4. Изменение температуры в зависимости от нагрузки при различных скоростях: - $-0.25 \mathrm{~m} / \mathrm{c}-0.5 \mathrm{~m} / \mathrm{c}$, $\Delta-0.75 \mathrm{M} / \mathrm{c}$.

Fig. 4. Change in temperature depending on load at different velocity: $-0.25 \mathrm{M} / \mathrm{c}, \mathbf{\square}-0.5 \mathrm{~m} / \mathrm{c}, \boldsymbol{\Delta}-0.75 \mathrm{M} / \mathrm{c}$. 


\section{4. Карты трения}

Разработка карт трения является полезным инструментом изучения и прогнозирования поведения пар трения при различных скоростях скольжения и нагрузках. Карты трения, предложенные Лимом и Эшби $[23,24]$, очерчивают четкие границы режимов трения, основанные на скорости скольжения и нормальной нагрузке. Ими были собраны обширные экспериментальные данные для стали, что позволило создать такие карты. Новые разработанные КМ требуют подобных исследований для построения карт трения. Интерес к таким картам состоит в том, чтобы предоставить инженерам информацию о поведении трибологической системы в заданных условиях трения скольжения.

Визуализация данных о проведенных испытаниях в виде карт делает удобным сравнение процессов трения и выбор оптимальных параметров режимов трения.

На Рис. 5 представлены карты режимов изнашивания исследованных образцов. Для построения карт изнашивания на плоскость были нанесены точки с координатами скорость/нагрузка для всех проведенных испытаний. Для скорости 0.25 м/с было проведено дополнительное испытание при нагрузке $3.5 \mathrm{MПа,}$ которое показало резкое увеличение интенсивности изнашивания ( $I m=6.45 \times 10^{-5} \mathrm{\Gamma} / \mathrm{M}$, на рисунке не показано). Около каждой точки указано соответствующее значение интенсивности изнашивания, Im.

Было выделено четыре режима изнашивания: мягкий, умеренный, жесткий и критический износ. Для разграничения режимов изнашивания сравнивали значения интенсивности изнашивания и поведение температурных кривых каждого этапа нагружения (Рис. 6).

Режим мягкого изнашивания характеризовался неизменностью температуры в процессе испытания, умеренное изнашивание - ростом значений температуры и выходом на плато. Жесткому режиму соответствовало нестабильное изменение температуры (пики, перегибы на графике), что может указывать на процессы образо-

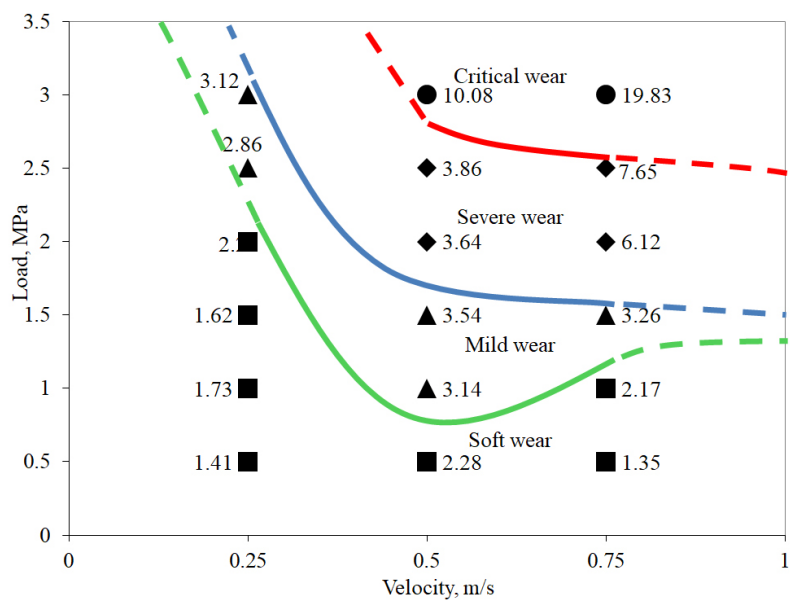

Pис. 5. (Color online) Карта режимов изнашивания. Размерность интенсивности изнашивания $-\times 10^{-5}$ г/м.

Fig. 5. (Color online) Wear modes map. Dimension of wear rate $\times 10^{-5} \mathrm{~g} / \mathrm{m}$.

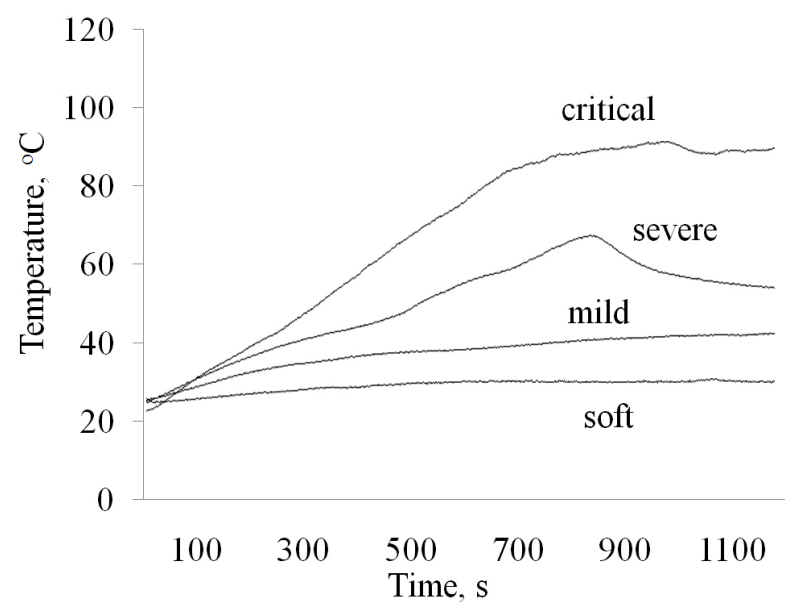

Рис. 6. Пример температурных кривых, скорость 0.5 м/с. Fig. 6. Example of temperature curves, velocity $0.5 \mathrm{~m} / \mathrm{s}$.

вания/разрушения «тела трения». Для критического режима характерна тенденция к постоянному резкому росту температуры во время испытания.

Предложены следующие границы режимов изнашивания:

- мягкое изнашивание $\operatorname{Im} \leq 2.655 \times 10^{-5} \mathrm{r} / \mathrm{M}$;

- умеренноеизнашивание $2.655 \times 10^{-5}<\operatorname{Im} \leq 3.59 \times 10^{-5} \mathrm{\Gamma} / \mathrm{M}$;

- жесткое изнашивание $3.59 \times 10^{-5}<\mathrm{Im} \leq 8.49 \times 10^{-5} \mathrm{\Gamma} / \mathrm{M}$;

- критическое изнашивание $\mathrm{Im}>8.49 \times 10^{-5}$ г/м.

На полученную карту режимов изнашивания нанесли значения коэффициентов трения в соответствующих точках (Рис. 7). Представленная информация позволяет выбрать точки, в которой процесс трения протекает с постоянной невысокой температурой, низким коэффициентом трения и небольшой интенсивностью изнашивания. Анализ приведенных данных показывает оптимальные параметры нагружения, соответствующие скорости 0.5 м/с и нагрузке 1.5 МПа. Построенные карты трения позволяют варьировать параметры трибонагружения для протекания процесса трения в области между мягким и умеренным изнашиванием.

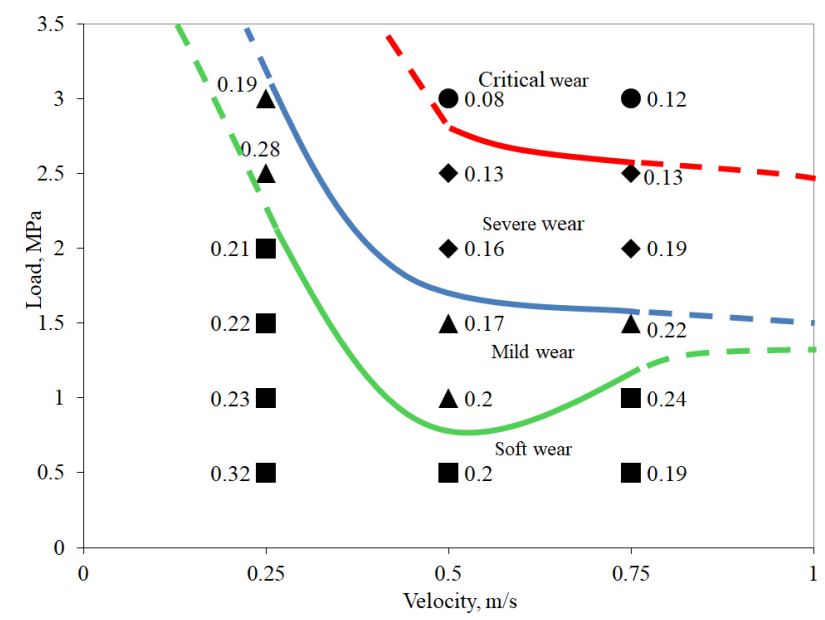

Pис. 7. (Color online) Карта распределения коэффициентов трения.

Fig. 7. (Color online) Friction coefficient map. 


\section{5. Заключение}

Проведены испытания на сухое трение скольжения композиционного материала на базе антифрикционного сплава АОМ20-01, упрочненного интерметаллидной фазой $\mathrm{Al}_{3} \mathrm{Ti}$ в диапазоне скоростей от 0.25 до $0.75 \mathrm{~m} / \mathrm{c}$ и нагрузок от 0.5 до 3.5 МПа и их комбинаций. Исследованы изменения интенсивности изнашивания, коэффициента трения и температуры трибопроцесса. Показано влияние нагрузки и скорости трения на исследованные параметры. Предложены четыре режима изнашивания КМ, для которых определены границы перехода от одного к другому. Построены карты интенсивности изнашивания и распределения коэффициентов трения, позволяющие выбрать оптимальные параметры трибонагружения с минимальными значениями коэффициентов трения и нормативными значениями по износу для узлов трения из исследованных КМ.

Благодарность / Acknowledgements. Работа выполнялась по государственному заданию ИМЕТ РАН № 075-00947-20-00. / This work was performed according to state assignment IMET RAS no. 075-00947-20-00.

\section{Литература / References}

1. R. Schouwenaars, V.H. Jacobo, A. Ortiz. Wear. 263, 727 (2007). Crossref

2. A.Kh. Valeeva, I.Sh. Valeev, R.F. Fazlyakhmetov, A.I. Pshenichnyuk. Letters on materials. 5 (2), 147 (2015). (in Russian) [А.Х. Валеева, И.Ш. Валеев, Р.Ф. Фазлыахметов, А.И. Пшеничнюк. Письма о материалах. 5 (2), 147 (2015).] Crossref

3. M.Q. Zeng, R.Z. Hu, K.Q. Song, L. Y. Dai, Z.C. Lu. Tribology Letters. 67, 84 (2019). ․ㅡossref

4. Z.C. Lu, Y. Gao, M. Q. Zeng, M.Zhu. Wear. 309 (1-2), 216 (2014). Crossref

5. V. Bhattacharya, K. Chattopadhyay. Acta Materialia. 52 (8), 2293 (2004). Crossref

6. T.A. Chernyshova, L.I. Kobeleva, P.A. Bykov, L.K. Bolotova, I.E. Kalashnikov, A.T. Volochko, A. Yu. Izobello. Inorganic Materials: Applied Research. 4 (3), 247 (2013). Crossref

7. S. Arunkumar, M. Subramani Sundaram, K. M. Sukethkanna, S. Vigneshwara. Materials Today: Proceedings. 33, 484 (2020). Crossref

8. V. Chak, H. Chattopadhyay, T.L. Dora. Journal of manufacturing processes. 56, 1059 (2020). $\underline{\text { Crossref }}$
9. G. Singh, S. Goyal. Particulate Science and Technology. 36 (2), 154 (2018). Crossref

10. T.A. Chernyshova, R.S. Mikheev, I.E. Kalashnikov, I. V. Akimov, E.I. Kharlamov. Inorganic Materials: Applied Research. 2 (3), 282 (2011). $\underline{\text { Crossref }}$

11. I.E. Kalashnikov, L.I. Kobeleva, L.K. Bolotova, P.A. Bykov, A.G. Kolmakov. Russian metallurgy (Metally). 4, 377 (2018). Crossref

12. F. Gul, M. Acilar. Composites Science and Technology. 64 (13-14), 1959 (2004). Crossref

13. A. V. Chichinadze, E. M. Berliner, E. D. Brown. Friction, wear and lubrication (tribology and tribotechnics) (ed. by A. V. Chichinadze). Moscow, Mashinostroenie (2003) 575 p. (in Russian) [А. В. Чичинадзе, Э.М.Берлинер, Э.Д. Браун. Трение, износ и смазка (трибология и триботехника) (под ред. А.В. Чичинадзе). Москва, Машиностроение (2003) 575 с.]

14. W. Tillmann, L. Hagen, M.D. Kensy, M. Abdulgader, M. Paulus. Journal of Thermal Spray Technology. 29, 1027 (2020). Crossref

15. N. Radhika, R. Raghu. Particulate Science and Technology. 36 (1), 104 (2018). Crossref

16. H.B. Michael Rajan, S. Ramabalan, I. Dinaharan, S. J. Vijay. Archives of Civil and Mechanical Engineering. 14 (1), 72 (2014). $\underline{\text { Crossref }}$

17. N. Radhika, R. Raghu. Transactions of Nonferrous Metals Society of China. 26 (4), 905 (2016). Crossref

18. M. Kumar, A. Megalingam. Particulate Science and Technology. 37 (3), 261 (2019). Crossref

19. M.A. Chowdhury, M.K. Khalil, D.M. Nuruzzaman, M. L. Rahaman. IJMME-IJENS. 11 (1), 53 (2011).

20. P.A. Bykov, L.I. Kobeleva, I.E. Kalashnikov, T.A. Chernyshova. Materialovedenie. 3, 27 (2011). (in Russian)[П.А.Быков, Л. И.Кобелева,И. Е.Калашников, T. А. Чернышова. Материаловедение. 3, 27 (2011).]

21. I.E. Kalashnikov, L.K. Bolotova, L.I. Kobeleva, P.A. Bykov, A.G. Kolmakov, R.S. Mikheev. Fizika i khimiya obrabotki materialov. 2, 65 (2020). (in Russian) [И.Е. Калашников, Л.К. Болотова, Л.И. Кобелева, П.А. Быков, А.Г. Колмаков, Р.С. Михеев. Физика и химия обработки материалов. 2, 65 (2020).] Crossref

22. N.B. Podymova, I.E. Kalashnikov, L.K. Bolotova, L. I. Kobeleva. Ultrasonics. 108, 106235 (2020). Crossref

23. S. C. Lim, M. F. Ashby. Acta Metallurgica. 35 (1), 1 (1987). Crossref

24. M. M. Stack. Tribology International. 35 (10), 681 (2002). $\underline{\text { Crossref }}$ 